\title{
Subgroup analysis of patients with HER2-negative metastatic breast cancer in the second-line setting from a phase 3, open-label, randomized study of eribulin mesilate versus capecitabine
}

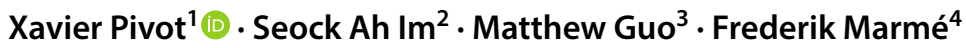

Received: 6 September 2017 / Accepted: 17 December 2017 / Published online: 4 January 2018

(c) The Author(s) 2018. This article is an open access publication

\begin{abstract}
This post hoc subgroup analysis of a large phase 3 study compared the efficacy and safety of eribulin versus capecitabine in patients with human epidermal growth factor receptor 2 (HER2)-negative metastatic breast cancer who received second-line treatment. In the phase 3 study, women with advanced/metastatic breast cancer and $\leq 3$ prior chemotherapies were randomized $1: 1$ to eribulin mesilate $1.4 \mathrm{mg} / \mathrm{m}^{2}$ intravenously on days 1 and 8 , or twice-daily oral capecitabine $1.25 \mathrm{~g} / \mathrm{m}^{2}$ on days 1-14 (21-day cycles). This analysis included 392 patients. Median overall survival was longer in patients receiving eribulin compared with capecitabine (16.1 vs 13.5 months, respectively; HR 0.77, $P=0.026$ ). Median progression-free survival and response rates were similar between arms. Both treatments had manageable safety profiles.
\end{abstract}

Keywords Subgroup analysis $\cdot$ Eribulin $\cdot$ Capecitabine $\cdot$ Metastatic breast cancer $\cdot$ Overall survival

\section{Introduction}

The prognosis for advanced or metastatic breast cancer $(\mathrm{MBC})$ remains poor, with a 5-year relative survival rate of $26 \%$ [1]. The backbone of treatment for human epidermal growth factor receptor 2 (HER2)-positive breast cancer includes anti-HER2 agents. However, for patients with HER2-negative tumors ( $75 \%$ of patients with breast cancer) [2] who have progressed following first-line chemotherapy, no single optimal treatment has been established. Current guidelines recommend the use of sequential monotherapy to balance efficacy and toxicity [3-5]. In the secondline setting, a limited number of chemotherapeutic regimens,

Xavier Pivot

xpivot@strasbourg.unicancer.fr

1 Paul Strauss Cancer Center, 3 rue de la porte de l'hôpital, BP30042-67065 Strasbourg, France

2 Seoul National University Hospital, Cancer Research Institute, Seoul National University College of Medicine, Seoul, Korea

3 Oncology Business Group, Eisai Inc., Woodcliff Lake, NJ, USA

4 National Centre for Tumour Diseases, Heidelberg and Department of Gynecologic Oncology, University Hospital, Heidelberg, Germany often administered in combinations, significantly prolonged survival [6-9]. Although single-agent capecitabine has not demonstrated a significant survival benefit after failure of chemotherapy, its safety profile makes it one of the most frequently used second-line therapies $[10,11]$.

Eribulin mesilate is a microtubule dynamics inhibitor with a distinct mode of action that involves binding to specific sites on the growing plus ends of microtubules $[12,13]$. In the pivotal phase 3 trial (Study 305/EMBRACE), eribulin significantly improved overall survival (OS) compared with treatment of physician's choice [14]. Study 301, which compared eribulin and capecitabine in locally advanced or MBC, showed that eribulin failed to demonstrate a statistically significant improvement in OS [hazard ratio (HR) 0.88; 95\% confidence interval (CI) $0.77-1.00 ; P=0.056$ ] [15]. However, a separate pooled analysis from Study 301 and Study 305, requested by the European Medicines Agency (EMA), which assessed treatment effect according to HER2 status, showed that eribulin improved OS in patients with HER2-negative MBC (HR 0.82; 95\% CI 0.72-0.93) [16], and specifically in the second-line or later setting (HR 0.85; 95\% CI 0.76-0.94) [17]. Based on the pooled analyses, the EMA extended eribulin's label to include routine use in a second-line setting [18]. Here, we present a post hoc subgroup analysis from Study 301 comparing the efficacy and 
safety of eribulin versus capecitabine as second-line treatment in patients with HER2-negative MBC.

\section{Methods}

The study design, eligibility criteria, and statistical analyses have been described in full previously [15] and are summarized here:

\section{Study design summary}

In the phase 3 (NCT00337103) open-label trial, patients were randomized $1: 1$ to receive eribulin mesilate $1.4 \mathrm{mg} / \mathrm{m}^{2}$ [equivalent to $1.23 \mathrm{mg} / \mathrm{m}^{2}$ eribulin (expressed as free base)] intravenously over 2-5 min on days 1 and 8, or capecitabine $1.25 \mathrm{~g} / \mathrm{m}^{2}$ orally twice daily on days $1-14$, both every 21 days, until disease progression, unacceptable toxicity, or patient/investigator request to discontinue. Patients were stratified by geographic region and HER2 status.

\section{Ethical approval}

All patients provided written informed consent. Approval was obtained from independent ethics committees and regulatory authorities in participating countries. The study was conducted in accordance with the World Medical Association Declaration of Helsinki, guidelines of the International Conference for Harmonisation/Good Clinical Practice, and local ethical and legal requirements.

\section{Patient population}

The primary study enrolled female patients aged $\geq 18$ years with histologically or cytologically confirmed locally advanced or $\mathrm{MBC}$, who had received $\leq 3$ prior chemotherapy regimens (of which no more than 2 for advanced and/or metastatic disease) and prior therapy with an anthracycline and a taxane. The present analysis included patients with HER2-negative tumors (HER2-negative/hormone receptorpositive and triple negative) treated in the second line. The co-primary endpoints were OS and progression-free survival (PFS); secondary endpoints included objective response rate (ORR) and safety.

\section{Statistical analysis}

Subgroup analysis was performed using the same statistical approaches (statistical model, missing data handling, and censoring rules) as the primary analysis. HRs of eribulin versus capecitabine were estimated in stratified Cox regression models with region as a stratification factor. $P$ values of treatment differences were estimated using a Cox model.
Table 1 Patient demographics and baseline characteristics (second line, HER2 negative, ITT population)

\begin{tabular}{|c|c|c|}
\hline \multirow[t]{2}{*}{ Characteristic } & \multicolumn{2}{|c|}{ Baseline, $n(\%)$} \\
\hline & $\begin{array}{l}\text { Eribulin } \\
(n=186)\end{array}$ & $\begin{array}{l}\text { Capecitabine } \\
(n=206)\end{array}$ \\
\hline \multicolumn{3}{|l|}{ Age } \\
\hline$\leq 40$ years & $16(8.6)$ & $36(17.5)$ \\
\hline$>40$ to $<65$ years & $135(72.6)$ & $150(72.8)$ \\
\hline$\geq 65$ years & $35(18.8)$ & $20(9.7)$ \\
\hline \multicolumn{3}{|l|}{ Geographic region } \\
\hline Eastern Europe & $99(53.2)$ & $112(54.4)$ \\
\hline Latin America & $39(21.0)$ & $37(18.0)$ \\
\hline Western Europe & $26(14.0)$ & $36(17.5)$ \\
\hline North America & $15(8.1)$ & $17(8.3)$ \\
\hline Asia & $5(2.7)$ & $3(1.5)$ \\
\hline South Africa & $2(1.1)$ & $1(0.5)$ \\
\hline $\begin{array}{l}\text { Disease progression within } 60 \text { days } \\
\text { after taking the last dose of taxane }\end{array}$ & $81(43.5)$ & $118(57.3)$ \\
\hline \multicolumn{3}{|l|}{ ER status } \\
\hline Positive & $104(55.9)$ & $116(56.3)$ \\
\hline Negative & $82(44.1)$ & $87(42.2)$ \\
\hline Not done & 0 & $3(1.5)$ \\
\hline \multicolumn{3}{|l|}{ Hormone-receptor status } \\
\hline Positive (ER- or PR-positive) & $113(60.8)$ & $129(62.6)$ \\
\hline Negative (both ER- and PR-negative) & $73(39.2)$ & $72(35.0)$ \\
\hline Not done & 0 & $5(2.4)$ \\
\hline Triple (HER2/ER/PR)-negative & $73(39.2)$ & $72(35.0)$ \\
\hline \multicolumn{3}{|l|}{ Number of organs involved } \\
\hline 1 & $37(19.9)$ & $27(13.1)$ \\
\hline 2 & $59(31.7)$ & $62(30.1)$ \\
\hline$\geq 3$ & $90(48.4)$ & $117(56.8)$ \\
\hline \multicolumn{3}{|l|}{ Site of disease $\mathrm{a}^{\mathrm{a}}$} \\
\hline Visceral & $154(82.8)$ & $187(90.8)$ \\
\hline Non-visceral only & $30(16.1)$ & $18(8.7)$ \\
\hline
\end{tabular}

$E R$ estrogen receptor, HER 2 human epidermal growth factor receptor 2, ITT intent to treat, $P R$ progesterone receptor

${ }^{\mathrm{a}}$ Visceral or non-visceral status was determined by independent assessment

Kaplan-Meier estimates and distribution curves were determined within each arm. Safety data were summarized descriptively using data from all patients who received at least 1 dose of study treatment and had at least 1 post-baseline safety evaluation. Adverse events (AEs) were graded using Common Terminology Criteria for Adverse Events v3.0; AEs were classified using the Medical Dictionary for Regulatory Activities. 
Fig. 1 a Overall survival: Kaplan-Meier plot for HER2negative patients (Study 301, second line, ITT population). b Progression-free survival: Kaplan-Meier plot for HER2negative patients (Study 301, second line, ITT population). CI confidence interval, HER2 human epidermal growth factor receptor 2, ITT intent-to-treat, $O S$ overall survival, $P F S$ progression-free survival

\section{(a) OS}

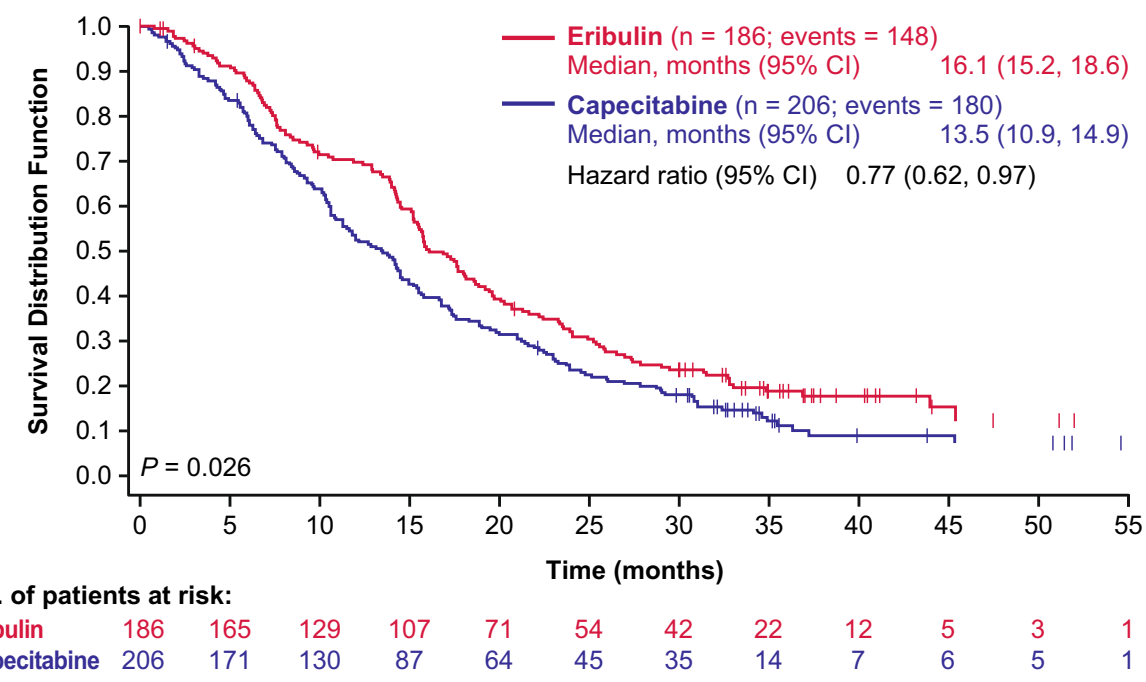

\section{(b) PFS}

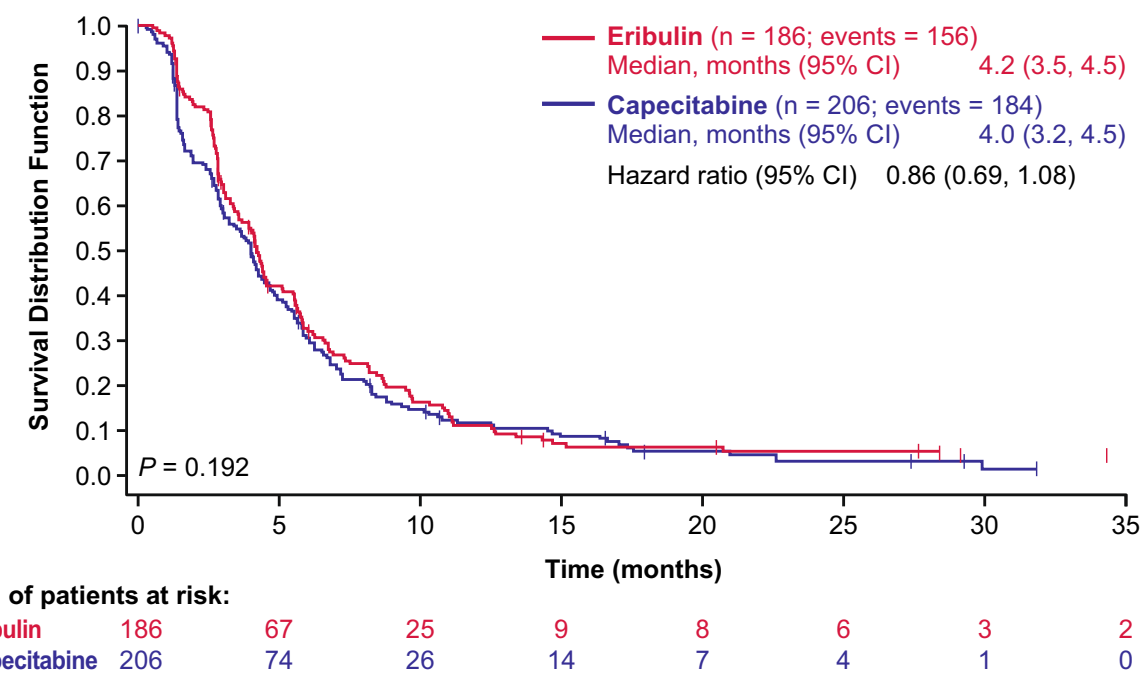

\section{Results}

\section{Patient characteristics}

Of the 1102 patients in Study 301, this analysis included 392 (36\%) patients with HER2-negative MBC who received second-line treatment. A total of 186 patients received eribulin and 206 patients received capecitabine. Baseline patient demographics and disease characteristics were generally well balanced between treatment arms with the exception of a smaller percentage of patients with $\geq 3$ organs involved (48.4 vs $56.8 \%$, eribulin vs capecitabine, respectively) and a larger percentage of patients with non-visceral disease ( 16.1 vs $8.7 \%$, eribulin vs capecitabine, respectively) in the eribulin group (Table 1).

\section{Efficacy}

In patients with HER2-negative $\mathrm{MBC}$ receiving treatment in the second line, OS was longer with eribulin treatment compared with capecitabine treatment (median OS, 16.1 vs 13.5 months, respectively; HR 0.77 ; $95 \%$ CI $0.62-0.97$; nominal $P=0.026$ ) (Fig. 1a). PFS based on investigator assessment was not different with eribulin treatment compared with capecitabine treatment (median PFS, 4.2 vs 4.0 months, respectively; HR 0.86 ; $95 \%$ CI $0.69-1.08$; nominal $P=0.192$ ) (Fig. 1b). ORRs were similar between treatment arms $(9.7 \%$ in the eribulin arm vs $8.7 \%$ in the capecitabine arm; $P=0.86)$. 
Table 2 TEAEs occurring at $>10 \%$ for any grade, or $>2 \%$ for grade 3 and 4

\begin{tabular}{|c|c|c|c|c|c|c|}
\hline \multirow[t]{3}{*}{ TEAEs, $n(\%)$} & \multicolumn{3}{|l|}{ Eribulin } & \multicolumn{3}{|c|}{ Capecitabine } \\
\hline & \multicolumn{3}{|l|}{$n=184$} & \multicolumn{3}{|l|}{$n=205$} \\
\hline & Any grade & Grade 3 & Grade 4 & Any grade & Grade 3 & Grade 4 \\
\hline Patients with any TEAE & $173(94.0)$ & $62(33.7)$ & $50(27.2)$ & $188(91.7)$ & $71(34.6)$ & $20(9.8)$ \\
\hline Patients with any SAE & $30(16.3)$ & $12(6.5)$ & $13(7.1)$ & $41(20.0)$ & $17(8.3)$ & $11(5.4)$ \\
\hline Patients with TEAEs leading to discontinuation & $15(8.2)$ & $8(4.3)$ & $2(1.1)$ & $18(8.8)$ & $6(2.9)$ & $4(2.0)$ \\
\hline Neutropenia & $98(53.3)$ & $43(23.4)$ & $37(20.1)$ & $30(14.6)$ & $10(4.9)$ & $1(0.5)$ \\
\hline Alopecia & $64(34.8)$ & 0 & 0 & $6(2.9)$ & 0 & 0 \\
\hline Leukopenia & $57(31.0)$ & $17(9.2)$ & $3(1.6)$ & $19(9.3)$ & $2(1.0)$ & $1(0.5)$ \\
\hline Peripheral neuropathy ${ }^{\mathrm{a}}$ & $44(23.9)$ & $12(6.5)$ & $1(0.5)$ & $17(8.3)$ & 0 & 0 \\
\hline Anemia & $39(21.2)$ & $2(1.1)$ & 0 & $40(19.5)$ & $1(0.5)$ & $1(0.5)$ \\
\hline Nausea & $38(20.7)$ & $1(0.5)$ & 0 & $43(21.0)$ & $2(1.0)$ & 0 \\
\hline Asthenia & $36(19.6)$ & $10(5.4)$ & 0 & $29(14.1)$ & $9(4.4)$ & 0 \\
\hline Decreased appetite & $29(15.8)$ & 0 & 0 & $32(15.6)$ & $2(1.0)$ & 0 \\
\hline Diarrhea & $26(14.1)$ & $2(1.1)$ & 0 & $51(24.9)$ & $13(6.3)$ & 0 \\
\hline Pyrexia & $26(14.1)$ & $1(0.5)$ & 0 & $10(4.9)$ & $1(0.5)$ & 0 \\
\hline Vomiting & $25(13.6)$ & $1(0.5)$ & 0 & $39(19.0)$ & $4(2.0)$ & 0 \\
\hline Fatigue & $25(13.6)$ & $2(1.1)$ & 0 & $26(12.7)$ & $2(1.0)$ & 0 \\
\hline Headache & $24(13.0)$ & $1(0.5)$ & 0 & $23(11.2)$ & 0 & 0 \\
\hline Dyspnea & $23(12.5)$ & $5(2.7)$ & $2(1.1)$ & $26(12.7)$ & $3(1.5)$ & $2(1.0)$ \\
\hline Back pain & $20(10.9)$ & $3(1.6)$ & 0 & $16(7.8)$ & $1(0.5)$ & 0 \\
\hline Cough & $15(8.2)$ & 0 & 0 & $21(10.2)$ & 0 & 0 \\
\hline Alanine aminotransferase increased & $14(7.6)$ & $6(3.3)$ & 0 & $8(3.9)$ & 0 & 0 \\
\hline Febrile neutropenia & $8(4.3)$ & $6(3.3)$ & $2(1.1)$ & $2(1.0)$ & 0 & $2(1.0)$ \\
\hline Palmar-plantar erythrodysesthesia syndrome & $1(0.5)$ & 0 & 0 & $99(48.3)$ & $28(13.7)$ & 0 \\
\hline
\end{tabular}

SAE serious adverse event, TEAE treatment-emergent adverse event

${ }^{a}$ Combines the following preferred terms: peripheral neuropathy, neuropathy peripheral, neuropathy, peripheral motor neuropathy, polyneuropathy, peripheral sensory neuropathy, peripheral sensorimotor neuropathy, demyelinating polyneuropathy, and paresthesia

\section{Safety}

The most frequent treatment-emergent AEs (TEAEs) in the eribulin arm were neutropenia (53.3\%), alopecia (34.8\%), leukopenia (31.0\%), peripheral neuropathy (pooled term, $23.9 \%$ ), and anemia (21.2\%) (Table 2). Grade 3 or 4 neutropenia occurred in $43.5 \%$ of patients in the eribulin arm. The most frequent TEAEs in the capecitabine arm were palmar-plantar erythrodysesthesia syndrome (48.3\%), diarrhea $(24.9 \%)$, nausea $(21.0 \%)$, anemia $(19.5 \%)$, and vomiting $(19.0 \%)$. Both treatment arms had manageable toxicities consistent with their known safety profiles.

\section{Discussion}

Treatment options for patients with HER2-negative MBC remain limited, with guidelines recommending singleagent chemotherapy [3-5]. Registration of a new agent in the metastatic setting beyond the first line requires demonstration of survival benefit [19]. In Study 301, eribulin did not demonstrate a significant survival benefit compared with capecitabine. However, it did show a heterogeneous treatment effect with a more favorable OS in patients with HER2-negative disease [15, 20]. Patient populations in large randomized trials such as this one are typically heterogeneous because of worldwide accrual, with a highly variable standard of care due to the range of drugs that may be licensed in each country.

A pooled analysis from Study 305 and Study 301, requested by the EMA, demonstrated that eribulin increased survival rates compared with control treatment in patients with HER2-negative MBC and provided support for an extension of its label to include routine use in a secondline setting $[16,17]$. In this post hoc subgroup analysis of Study 301, which evaluated patients with HER2-negative $\mathrm{MBC}$ receiving eribulin or capecitabine as second-line treatment, prolonged OS benefit with the use of eribulin versus capecitabine was observed, supporting its activity as a second-line treatment for patients with HER2-negative MBC. Disease characteristics in both treatment groups were generally similar with the exception of a smaller percentage of 
patients with $\geq 3$ organs involved and a larger percentage of patients with non-visceral disease in the eribulin group. Both treatments had manageable, non-overlapping, safety profiles. These findings, although exploratory, may aid in treatment decisions in the absence of prospective study data in patient populations that match the approved European Union indication for eribulin. Other factors may be considered in treatment decisions for second-line therapy, including toxicity profiles, residual effects from prior chemotherapy regimens, and modality of administration.

Acknowledgements We thank all the patients and investigators who participated in this study (please refer to Kaufman et al. [15] for the full list).

Funding The primary study was sponsored by Eisai, Inc. Medical writing support was provided by Oxford PharmaGenesis, and was funded by Eisai, Inc.

\section{Compliance with ethical standards}

Conflict of interest XP declares no conflicts of interest. SAI declares an advisory board role with Novartis, Hanmi, and Spectrum. MG is an employee of Eisai, Inc. FM has received consulting honoraria from Eisai, Roche, Novartis, Amgen, PharmaMar, and AstraZeneca.

Open Access This article is distributed under the terms of the Creative Commons Attribution 4.0 International License (http://creativecomm ons.org/licenses/by/4.0/), which permits unrestricted use, distribution, and reproduction in any medium, provided you give appropriate credit to the original author(s) and the source, provide a link to the Creative Commons license, and indicate if changes were made.

\section{References}

1. National Cancer Institute. SEER cancer statistics factsheets: female breast cancer. http://seer.cancer.gov/statfacts/html/brea st.html. Accessed 24 Apr 2017.

2. Howlader N, Altekruse SF, Li CI, Chen VW, Clarke CA, Ries LA, et al. US incidence of breast cancer subtypes defined by joint hormone receptor and HER2 status. J Natl Cancer Inst. 2014. http s://doi.org/10.1093/jnci/dju055.

3. Cardoso F, Costa A, Norton L, Cameron D, Cufer T, Fallowfield $\mathrm{L}$, et al. 1st International consensus guidelines for advanced breast cancer (ABC 1). Breast. 2012;21:242-52.

4. National Comprehensive Cancer Network Clinical Practice Guidelines in Oncology (NCCN Guidelines ${ }^{\circledR)}$. Breast Cancer. Version 2.2017. https://www.nccn.org/professionals/physician_gls/pdf/ breast.pdf. Accessed 24 Apr 2017.

5. Partridge AH, Rumble RB, Carey LA, Come SE, Davidson NE, Di Leo A, et al. Chemotherapy and targeted therapy for women with human epidermal growth factor receptor 2-negative (or unknown) advanced breast cancer: American Society of Clinical Oncology Clinical Practice Guideline. J Clin Oncol. 2014;32:3307-29.

6. Jones S, Winer E, Vogel C, Laufman L, Hutchins L, O'Rourke $\mathrm{M}$, et al. Randomized comparison of vinorelbine and melphalan in anthracycline-refractory advanced breast cancer. J Clin Oncol. 1995;13:2567-74.

7. Nabholtz JM, Senn HJ, Bezwoda WR, Melnychuk D, Deschênes L, Douma J, et al. Prospective randomized trial of docetaxel versus mitomycin plus vinblastine in patients with metastatic breast cancer progressing despite previous anthracyclinecontaining chemotherapy. 304 Study Group. J Clin Oncol. 1999;17:1413-24.

8. Albain KS, Nag SM, Calderillo-Ruiz G, Jordaan JP, Llombart AC, Pluzanska A, et al. Gemcitabine plus Paclitaxel versus Paclitaxel monotherapy in patients with metastatic breast cancer and prior anthracycline treatment. J Clin Oncol. 2008;26:3950-7.

9. O'Shaughnessy J, Miles D, Vukelja S, Moiseyenko V, Ayoub JP, Cervantes G, et al. Superior survival with capecitabine plus docetaxel combination therapy in anthracycline-pretreated patients with advanced breast cancer: phase III trial results. J Clin Oncol. 2002;20:2812-23.

10. Ershler WB. Capecitabine monotherapy: safe and effective treatment for metastatic breast cancer. Oncologist. 2006;11:325-35.

11. von Minckwitz G, Puglisi F, Cortes J, Vrdoljak E, Marschner $\mathrm{N}$, Zielinski C, et al. Bevacizumab plus chemotherapy versus chemotherapy alone as second-line treatment for patients with HER2-negative locally recurrent or metastatic breast cancer after first-line treatment with bevacizumab plus chemotherapy (TANIA): an open-label, randomised phase 3 trial. Lancet Oncol. 2014;15:1269-78.

12. Dybdal-Hargreaves NF, Risinger AL, Mooberry SL. Eribulin mesylate: mechanism of action of a unique microtubule-targeting agent. Clin Cancer Res. 2015;21:2445-52.

13. Smith JA, Wilson L, Azarenko O, Zhu X, Lewis BM, Littlefield BA, et al. Eribulin binds at microtubule ends to a single site on tubulin to suppress dynamic instability. Biochemistry. 2010;49:1331-7.

14. Cortes J, O'Shaughnessy J, Loesch D, Blum JL, Vahdat LT, Petrakova K, et al. Eribulin monotherapy versus treatment of physician's choice in patients with metastatic breast cancer (EMBRACE): a phase 3 open-label randomised study. Lancet. 2011;377:914-23.

15. Kaufman PA, Awada A, Twelves C, Yelle L, Perez EA, Velikova G, et al. Phase III open-label randomized study of eribulin mesylate versus capecitabine in patients with locally advanced or metastatic breast cancer previously treated with an anthracycline and a taxane. J Clin Oncol. 2015;33:594-601.

16. Twelves C, Cortes J, Vahdat L, Olivo M, He Y, Kaufman PA, et al. Efficacy of eribulin in women with metastatic breast cancer: a pooled analysis of two phase 3 studies. Breast Cancer Res Treat. 2014;148:553-61

17. Pivot X, Marmé F, Koenigsberg R, Guo M, Berrak E, Wolfer A. Pooled analyses of eribulin in metastatic breast cancer patients with at least one prior chemotherapy. Ann Oncol. 2016;27:1525-31.

18. Eisai Europe Limited. Halaven $0.44 \mathrm{mg} / \mathrm{ml}$ solution for injection [summary of product characteristics]. Hertfordshire, UK.

19. Pivot X. Classic cytotoxic drugs: a narrow path for regulatory approval. Lancet Oncol. 2017;18:279-81.

20. Twelves C, Awada A, Cortes J, Yelle L, Velikova G, Olivo MS, et al. Subgroup analyses from a phase 3, open-label, randomized study of eribulin mesylate versus capecitabine in pretreated patients with advanced or metastatic breast cancer. Breast Cancer (Auckl). 2016;10:77-84. 